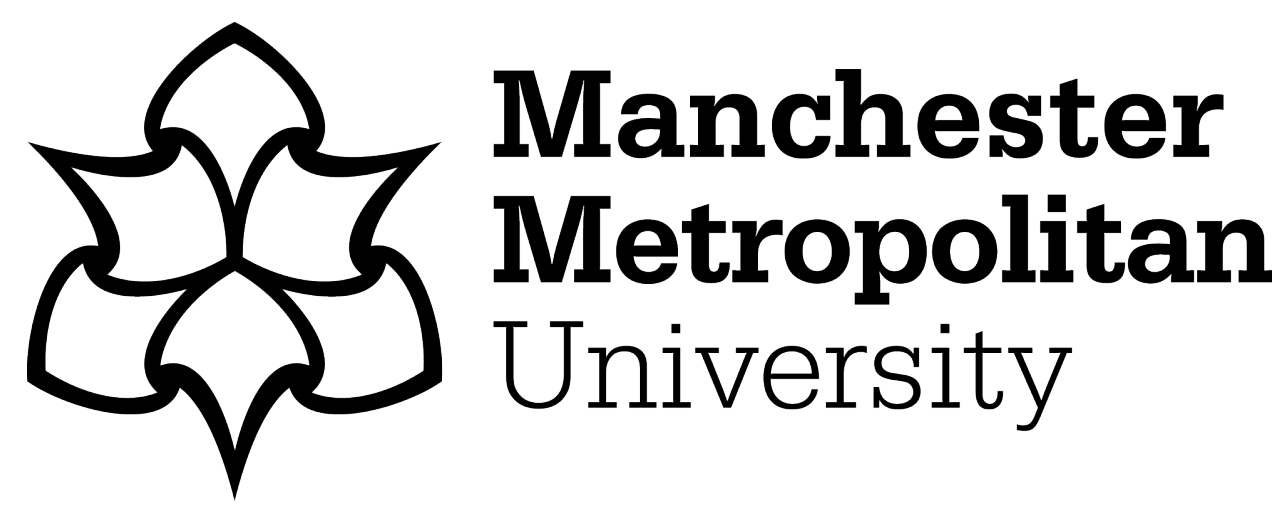

Lewis, Ingrid, Corcoran, Su Lyn, Juma, Said, Kaplan, Ian, Little, Duncan and Pinnock, Helen (2019) Time to stop polishing the brass on the Titanic: moving beyond 'quick-and-dirty' teacher education for inclusion, towards sustainable theories of change. International Journal of Inclusive Education, 23 (7-8). pp. 722-739. ISSN 1360-3116

Downloaded from: https://e-space.mmu.ac.uk/623183/

Version: Accepted Version

Publisher: Taylor \& Francis (Routledge)

DOI: https://doi.org/10.1080/13603116.2019.1624847

Please cite the published version 


\section{Time to stop polishing the brass on the Titanic: Moving beyond 'quick-and-dirty' teacher education for inclusion, towards sustainable theories of change}

Ingrid Lewis $^{1}$, Su Lyn Corcoran ${ }^{1 \& 2}$, Said Juma ${ }^{1 \& 3}$, Ian Kaplan ${ }^{1 \& 4}$, Duncan Little ${ }^{1}$ and Helen Pinnock $^{1}$

${ }^{1}$ Enabling Education Network - EENET

${ }^{2}$ Education and Social Research Institute, Manchester Metropolitan University

${ }^{3}$ State University of Zanzibar

${ }^{4}$ Norwegian Afghanistan Committee

Corresponding author(s) details:

Ingridlewis@eenet.org.uk

su.corcoran@mmu.ac.uk

Article submiited to the International Journal of Inclusive Education:

Ingrid Lewis, Su Lyn Corcoran, Said Juma, Ian Kaplan, Duncan Little \& Helen

Pinnock (2019): Time to stop polishing the brass on the Titanic: moving beyond 'quick-and-dirty'

teacher education for inclusion, towards sustainable theories of change, International Journal of Inclusive Education, DOI: 10.1080/13603116.2019.1624847 


\title{
Time to stop polishing the brass on the Titanic: Moving beyond 'quick- and-dirty' teacher education for inclusion, towards sustainable theories of change
}

\author{
Abstract \\ Interest in inclusive education in the global south has grown significantly since \\ the adoption of the Salamanca Statement in 1994. Increasingly, those who fund \\ and provide education want to be seen taking action on inclusion generally and \\ disability inclusion specifically. However, the much-welcomed enthusiasm to \\ respond to global commitments is not always matched with the necessary \\ expertise and commitment to longer-term action and change. The growth in \\ inclusive education policies and pilot projects in the last decade is hard to miss, \\ but changes resulting from these interventions are often less apparent. Why is \\ that? Drawing on the Enabling Education Network's 22 years of experience as a \\ global inclusive education network and consultancy provider, we present \\ alternative pathways for change in teacher education for inclusion. We stress \\ that change in teaching practice remains limited not because inclusive education \\ is a fundamentally flawed concept, but because too much focus is given to \\ 'quick-and-dirty' trainings that quickly yield donor-pleasing statistics and \\ publicity-attracting case studies, but fail to elicit sufficiently extensive and \\ sustainable change to education systems and cultures.
}

Key Words: Theory of change; Sustainability; Teacher education; Teacher training 
Guidance on implementing inclusive education in resource-limited contexts typically explains this as a long-term process of change. But how long is long? The Salamanca Statement and Framework for Action on Special Needs Education was adopted in 1994, providing a ground-breaking call that learners with 'special educational needs must have access to regular schools which should accommodate them within a child centred pedagogy capable of meeting these needs' (UNESCO 1994, 3). Has 25 years been long enough to see progress in the process of change towards inclusive education? Yes and no.

In this article, we draw on the Enabling Education Network's (EENET) 22 years of experience as a global inclusive education network to briefly summarise some of the progress and ongoing challenges regarding inclusive education in the global south. We focus on the assumptions that appear to underpin inclusive education teacher education programmes in this context, arguing that assumptions are often inaccurate and lead to erroneous theories of change, which undermine investments in teacher education. With evidence from EENET's experience in Zambia, Zanzibar and globally, we present alternative assumptions that could lead to effective pathways for change.

\section{Evidence of and Challenges to Progress since Salamanca}

The Salamanca Statement, and subsequent international calls to action, frame ambitious visions of desired change across the education system and there has been important progress made at policy level with regard to inclusive education. The global education community is increasingly prioritising the concept, albeit with diverse interpretations of what it means in practice. The last quarter century has seen 177 countries ratify the UN Convention on the Rights of Persons with Disabilities (UNCRPD), in which Article 24 clarifies that states parties have a responsibility to 'ensure an inclusive education system at all levels' (UN 2006). It has also seen the adoption of the Sustainable Development Goals (SDGs), in which Goal 4 is to 'ensure inclusive and equitable quality education and promote lifelong learning opportunities for all' - recognising the central importance of quality education to inclusion (UN 2015).

'Quality’, ‘inclusion’ and ‘disability-inclusion’ are increasingly referenced in international aid and non-governmental organisation (NGO) education programmes. The International 
Disability and Development Consortium Inclusive Education Task Group (IDDC 2016) report - \#CostingEquity. The case for disability-responsive education financing - specifically outlines the benefits of financing disability-inclusive education. The UK Department for International Development (DFID), for example, recently prioritised disability inclusion within several education programmes, including the most recent phase of the Girls' Education Challenge grant fund and programmes in Sierra Leone and Rwanda (DFID 2018a, 2018b). At national level, various governments have begun developing good quality inclusive education policies, including Namibia (MoE 2013) and Palestine (MEHE 2015). Sometimes, however, national inclusive education policies remain special education policies with just superficial terminology revisions, and/or remain isolated policies while core education policies go unchanged.

Outside of these policy advances exists a mixed picture of progress and frustrations. Commitments to Education for All, reinforced by the Millennium Development Goals (MDGs) brought substantial increases in primary enrolment. Globally, numbers of out-ofschool primary-age girls fell from around 65 million in 1994 to around 33 million in 2017; boys from 44 million to 29 million. ${ }^{1}$ However, despite the enrolment statistics, many learners, especially from marginalised groups, receive a low-quality education and achieve poor learning outcomes (UN 2018). While initial access to education may be improving for marginalised groups (e.g. Ackah and Danso [2019]; UN [2018, 6]), retention and achievement are not.

There is increased interest in and budgets for 'quality education' and 'inclusive education', but with an estimated 33 million children with disabilities out of school in low- and middleincome countries (Education Commission 2016, 33) and growing achievement gaps between children with and without disabilities, there remains a need for education system transformation (Male and Wodon 2017). The importance of looking beyond enrolment figures to address 'persistent deficiencies in provision and quality' is becoming a stronger concern (e.g. UNESCO 2017, 3). Governments, NGOs and UN agencies are developing quality education and inclusive education programmes that include training teachers, in recognition of their central role in inclusive education. Unfortunately, education programme 
design often fails to recognise explicitly the inherent connections between quality education and inclusive teaching and the assumptions that underpin action in this area.

A growth in small-scale, NGO and donor-supported inclusive education projects in the global south is tempered by ongoing prevalence of special needs-focused work labelled as inclusive education, but really being a form of integration. As Byrne $(2012,235)$ notes, '... when used synonymously to refer to little more than integration, the concept of inclusion risks becoming misleading, ideologically meaningless and riddled with ambiguities; reminiscent of a sheep in lion's clothing'. Promising 'pilot' projects often fail to progress beyond small-scale trials (McClure and Gray 2015) (for many reasons beyond the scope of this paper), while projectbased efforts to engage and support parents and communities in whole-school improvement remain 'pockets of good practice' rather than an education system-wide norm.

The systemic changes required to bring about inclusive education are not achievable within the restricted timescales of project-based initiatives focused on easily measurable inputs, outputs and outcomes. Yet a story of naïve expectations for huge education change from often minimal, superficially attractive inputs is playing out across developing country contexts. This is particularly visible in teacher education where, judging by the many project plans and evaluations we have reviewed, it seems typical for NGOs and government partners to expect teachers to transform their practice following just a 5-day theory-oriented inclusive education workshop.

\section{Materials and methods}

Since 1997, EENET has encouraged and supported mostly grassroots education stakeholders (including teachers, parents, students, local NGO staff and government officials) to critically reflect on, document and share their inclusive education experiences in accessible, easy-read formats. The focus has been on promoting problem-solving in contexts where innovation is essential because resources are minimal (Miles and Ahuja 2007). For over a decade we have also offered consultancy support to NGOs, disabled people’s organisations (DPOs), UN agencies and governments, providing us in turn with privileged access to information about inclusive education practice on the ground. Such information - 'particularly research examining the facilitating and constraining factors influencing NGO performance' (Kareithi 
and Lund 2011) - is rarely published, especially in peer reviewed academic sources. Disconnection between academic research and international development, and a limited capacity among NGOs to research inclusive education to 'academic' standards, is anchored by the weight of literature still sitting behind paywalls rather than being open access.

Consequently, valuable evidence about the development of inclusive education in the global south remains hidden in confidential reports, or is published (e.g. via EENET's website and annual Enabling Education Review) but overlooked by researchers because of its nonacademic format. Here, we draw on evidence from our global networking, documenting and consultancy activities, much of which is not validated in peer-reviewed sources, but is, we believe valuable for those seeking to learn more about inclusive education in these contexts. We also draw on the consultation processes used to inform the development of EENET's theory of change (ToC) in 2016, and related periodic reflective processes to review the assumptions underpinning the ToC.

EENET's ToC focuses on three domains of change relevant to our mandate as an information network (Lewis 2016). These are improving stakeholder capacity to: work collaboratively, to learn from experience and exchange learning, and to influence other stakeholders to effect positive change towards inclusive education. Our pathways of change illustrate that change in these three domains requires education practitioners, advocates, decision-makers, funders and other stakeholders to be critical, analytical thinkers and problem-solvers preconditions endorsed by many commentators (Florian and Linklater 2010) - and that little progress will happen without such preconditions being met (Ainscow 2013; Ainscow and Sandhill 2010). ${ }^{2}$

\section{Common Underlying Assumptions}

Every development initiative is based on fundamental assumptions, ideally explicitly expressed in project design documents describing the project's logic for change. In reality, many development projects are founded on implicit assumptions (Prinson and Nijhof 2015; Stein and Valters 2012). By not articulating assumptions that underpin projects, false assumptions can persist unchallenged for years. 
Five common assumptions that appear to underpin current design of inclusive teacher education are discussed below. We have identified these through document analysis over the last decade (including of: project proposals, plans and logical frameworks; terms of reference for project baseline studies and evaluations; project case studies and NGO publicity materials), and through numerous interviews and meetings with diverse international and national NGO representatives.

Assumption 1 - serving teachers can be trained effectively on inclusive education within a short project cycle

A pervasive assumption in NGO and donor-supported project plans, reports, case studies and evaluations is that practice among serving teachers can be significantly changed within one or two years (a typical donor-funded project timeframe). This is not in itself a false assumption; if a cadre of teachers received high quality, on-going learning opportunities and support throughout a 1-2-year period they would likely improve their capacity and confidence to teach diverse learners. In reality, each group of serving teachers usually receives just one short (typically five days) training.

Projects are frequently designed to reach as many teachers as possible during short funding periods, rather than working intensively with fewer teachers to produce meaningful, sustainable change - an astounding prioritisation of quantity-over-quality. One recent confidential terms of reference for technical assistance in a major international donor-funded project in a middle-income country sought to deliver a five-day in-service training package to 5,000 teachers, from which 500 would be selected (on the basis of end-of-training scores) to cascade the training to thousands more teachers. (Selecting trainers in this way reflects existing trends for teacher recruitment, which equate high achievement in exams with teaching prowess (e.g. DfE 2018)). These massive roll-out numbers were to be achieved in under three years - a naïve expectation that ignores teachers' humanity, as we explain further.

Assumption 2 - teachers are programmable machines who just need to memorise simple factual messages about inclusive education 
What can a teacher realistically learn about inclusive education in a five-day workshop? Many NGO and donor-supported in-service trainings are theory-based - participants are told what inclusive education means and receive pointers on how to 'do' it but rarely have opportunities to practise new behaviours in a classroom, or observe someone else demonstrating different ways of working. The following teacher voice represents many from the evaluations we have conducted or reviewed:

"It is a bit challenging to get short training and then implement inclusion in class as the situation is more difficult in real life" (male teacher...)

(Lewis 2014)

We see disconnection in inclusive education projects designed to help stakeholders rethink how children learn, but which lack similar rethinking about how adults (teachers) learn. While participatory, active learning is routinely acknowledged as key to developing inclusive classrooms (Laluvein 2010), such pedagogy remains absent in many inclusive education teacher training initiatives. Teachers are not accorded respect as adult learners with diverse learning preferences and needs. Failure to become inclusive after one short workshop may even be considered 'resistance': e.g. 'the trainees' perceptions are hardened' declared one trainer in Armenia (Lewis 2011, 33). Inclusive education theory explains that learners' failure to achieve is due to the (in)actions of teachers, curriculum developers, etc. But in our experience, when a teacher fails to become inclusive after a short training course, there is insufficient critical reflection on the role of the trainer, the course, the training approach or other contextual factors. We know this because similarly flawed approaches reappear, year after year, in NGO project plans, consultancy terms of reference, and evaluation reports, suggesting lessons are not learned and responsibility for training 'failure' is too often carried by teacher training participants.

"The burden was put on the shoulders of the teachers because we had just one training with them and it's not enough.” (inclusive education specialist)

(Lewis 2011, 32)

The tendency to position teachers as responsible for the success or failure of inclusive education training is echoed in the numerous academic research projects focused on teacher affinity/efficacy for inclusion. EENET colleagues working in academia repeatedly meet prospective $\mathrm{PhD}$ students wanting to investigate how 'ready' teachers are for inclusion and 
how much teacher affinity changes after brief trainings. Research is also being conducted into measuring teacher affinity in order to understand whether inclusion is possible in particular schools and if teachers are prepared enough to teach inclusively (Sharma et al. 2012). We no longer accept that it is the child's fault if they fail to learn, yet it still seems acceptable to blame teachers rather than the training and support available to them.

\section{Assumption 3 - it is only viable for NGOs to engage with in-service training}

The problem of ensuring all teachers can confidently teach inclusively would be substantially reduced if all student teachers learned about inclusion throughout their pre-service training. Unfortunately, across many global south countries, pre-service training lacks investment, innovation and relevance (Westbrook et al. 2013). Inclusive education, if dealt with at all, tends to be covered in stand-alone (often optional) modules, and/or conflated with special education or disability-awareness modules. Pre-service interventions are far outnumbered by NGO-supported in-service trainings, and this is reflected in the literature (Rieser 2013). This is not always the case globally. For example, Ireland began increasing the length of all undergraduate and postgraduate teaching programmes in 2012 to ensure initial teacher education for inclusion, with some promising results (Hick et al. 2018).

Teacher education is a government responsibility, implying that pre-service training requires 'more complex buy in from governments that NGOs are not always able or willing to work towards’ (Rieser 2013: 52). In-service training is undoubtedly simpler to address. NGOs can more easily get government permission to deliver a few in-service courses, than influence curricula or directly intervene with delivering courses in pre-service institutions. Arguably, there is also the pressure of visibility; in-service interventions, especially cascade-based models, can - quickly and relatively cheaply - yield high reach statistics that look impressive to donors, government partners and the public.

Assumption 4 - anyone can manage or deliver inclusive education teacher training

We hypothesize that some of the most influential education-focused organizations are advancing their agendas by engaging media and drawing on individuals who possess 
substantial media acumen, yet may not possess traditionally defined educational expertise. (Malin and Lubienski 2015, 1)

These US education researchers used publicly available data on education and employment histories to determine relative levels of education expertise among those making or influencing education decisions. Using publicly available LinkedIn profile data, we recently did our own rapid analysis of NGO/donor personnel with whom we have worked on inclusive education projects, to see how many had direct education expertise (e.g. as teachers, head teachers, special needs teachers or assistants, school administrators, education researchers, education policy-makers, etc.). More than half of those responsible for managing, advising or training on education or inclusive education appeared to have little or no experience in education or teaching. Looking back on the NGO and donor colleagues we have worked with in the last 25 years we see a growing trend towards inclusive education projects designed, managed and implemented by individuals, and sometimes whole teams, who have never worked in or taught in a school or managed at any level in an education system. In part, this may be because many inclusive education projects are run by disability-focused NGOs, whose personnel provide disability expertise in lieu of education expertise. Nevertheless, some of the flawed teacher education assumptions we outline here may appear or persist because key personnel do not have the first-hand experience of teaching contexts necessary to inform the assumptions on which they plan their projects.

The lack of recognition for the importance of experience and skills - and crucially of attitudes and values - in teacher education for inclusion is seen in the preponderance of simplistic cascade training programmes within NGO portfolios (DEVCO 2014; Popova et al. 2016). Such programmes assume any teacher can receive minimal training on inclusive education and then switch hats overnight to become an effective pro-inclusion trainer. However, if these newly created trainers do not have a wealth of experience and ideas to draw on, nor a solid belief in the principles of inclusion, then the cascade model 'supports a technicist view of teaching, where skills and knowledge are given priority over attitudes and values’ (Kennedy 2005). 
Assumption 5 - inclusive education is too challenging for teachers working in difficult circumstances

Within a number of settings in the global south - especially in crisis or low-resource situations - teachers may have minimal or no training before becoming teachers. They can be stereotyped as unable to learn well, or too poorly motivated to tackle anything beyond the bare minimum job requirements. This fundamental lack of faith in teachers leads to beliefs among NGO and government personnel that efforts to bring about 'good teaching' will not work with these teachers. It also leaves the door open for private-sector interventions - such as the Bridge International Schools model - that deskill and dehumanise teachers through supposedly cost-effective use of standardised and technologically automated teaching approaches (Anderson 2017; Riep and Machacek 2016).

In our experience, in relation to inclusive education, lack of faith in teachers can lead to NGOs deliberately prioritising school infrastructure/equipment interventions, or even funding separate special units, because they believe regular teachers are too incapable or demotivated to make a success of any inclusion training offered. Evidence of teachers 'resisting' inclusive education training has been cited to us as justification for such decisions. However, as we noted above, teachers are likely to push back against inclusive education if the training is poor quality, or because they need more time to adjust to changes in practice that contradict what they learned in pre-service training or experienced throughout their own education career, not because they are fundamentally unable to learn new skills or adjust their attitudes. Any apparent resistance to inclusive education among teachers needs to be taken seriously, with root causes identified and addressed, slowly and sympathetically, which in our experience, few NGO and donor-supported training programmes do.

\section{Alternative Assumptions and Approaches}

Recent systematic reviews and meta-analyses have considered the global evidence on strengthening teaching practice to improve learning and reduce education disparities (3ie 2016; Bolton 2018; ESRC 2018; Evans \& Popova 2016). These studies recommend professional development, which: prioritises in-depth, structured pedagogical development over time with frequent follow-up; promotes mutual support between teachers; and delivers capacity building at or close to school level. This is quite different from the types of 
interventions mentioned above. So what could or should NGO and donor-supported interventions do differently to ensure they help improve inclusive education teacher education? We draw on experience from an approach used in Zambia and Zanzibar to illustrate alternative assumptions underpinning project design, the consequent interventions and emerging results.

The project was started by Norwegian Association for Persons with Developmental Disabilities (NFU) in 2015. As a partner in inclusive education in Zanzibar for over a decade NFU had encouraged a shift from cascade to whole-school in-service training (Juma and Lehtomäki 2015) and had extensive experience supporting community-based inclusive development in Zambia. A 2013 evaluation in Zanzibar recommended teacher training improvements including embedding action research in teacher professional development (Juma et al. 2017a). The project was handed over to Norwegian Association of Disabled (NAD) in 2016 when NFU withdrew from international work. In both countries, the project was implemented in partnership with the ministries of education and EENET provided longterm technical assistance. Design and implementation were similar in both countries so we will consider them together.

The project involved developing seven in-service teacher training modules (with four more pending) to be delivered by a cadre of trained trainers (McKinney 2019). Training would initially be done in a small number of pilot schools (eight in Zanzibar and six in Zambia), with a view to expansion in later years. Although this seems similar to interventions discussed already, important variations will emerge.

The main assumption underpinning project design was that effective teacher education for inclusion does not emerge when constrained by funding timelines and pressure to reach large numbers of teachers quickly. Therefore, a project was planned with at least four years of support and probable extension. The training content was designed to be accumulative. Teachers would not simply receive one five-day overview of inclusive education theory but instead - over a period of at least a year - be immersed in learning about a series of increasingly specific inclusion topics. This was based on the premise that all teachers can learn to be inclusive, even when working in difficult, resource-limited contexts, if realistic 
learning approaches are used and time is taken to understand behaviours and attitudes hitherto dismissed as 'resistance to inclusion'.

The project considered carefully the assumption that teachers are adult learners with complex learning requirements. It sought a training programme to give teachers time and space for learning at a realistic pace, with opportunities for critical reflection and experiential learning. Consequently, training modules not only use participatory, active learning pedagogy, but also include action research assignments for teachers in between each module workshop. Teachers document their action research and discuss with colleagues at subsequent workshops.

The project design took a further step to consider the needs of teachers as adult learners living and working in a specific context. Rather than have an external consultant write and hand over training materials, a detailed process of co-development was facilitated. The cadre of trainers who would be responsible for rolling out the training (see below) actively codeveloped the training messages and methods. Outlines of each module were developed by an external facilitator, building on information gathered during scoping visits and consultations with stakeholders (including teachers, trainers, learners). The team of trainers then experienced receiving and facilitating the training, suggesting modifications and inserting contextually relevant case studies and activities that would resonate with teaching colleagues.

The assumption common in cascade models, that anyone can train others on inclusive education, was firmly rejected. Instead the project built on the assumption that greater success emerges when trainers are carefully chosen. The cadre of trainers who worked collaboratively on co-developing and rolling out the training modules was selected from personnel with existing teacher training experience, support or monitoring mandates, such as lecturers from universities and teacher training colleges, district education officials, advisers from school cluster 'teacher centres' and pilot school head teachers. This helped ensure they were not totally novice trainers and improved sustainability by adding inclusive education expertise onto existing teacher professional development and/or school improvement responsibilities. 
The project recognised that stereotypical perceptions of teachers as unwilling to learn could emerge if participating teachers felt overwhelmed by and pushed back against the prospect of having to implement everything they were learning. The training therefore supported the development of multi-stakeholder school inclusion teams (involving teachers, learners, parents, community leaders/members and others), to assist teachers with identifying learners' needs and absent learners, and in finding low/no-cost solutions to presence, participation and achievement barriers. A module on developing the role of a school inclusive education coordinator was also added later, at the request of trainers and pilot school teachers.

The assumption that learning about inclusive education involves transferring and remembering facts or instructions was refuted in favour of placing critical thinking and reflection at the core, for instance by embedding action research activities in the training modules. Observer groups of personnel with existing roles as inspectors, teacher centre coordinators, senior district education officials, and DPO and local health authority staff were also established and trained. Observers - trained to use the participatory action research tools used by teachers to elicit opinions and experiences from learners, teachers and parents - visit schools receiving in-service training to observe progress. Initially they were expected to visit schools after each training module (2-3 modules per year), but for logistical and financial reasons they now visit annually. The observers feed back to trainers and teachers, offering critical reflection and dialogue to inform teachers' practice and adaptations to training messages and methods.

The final assumption underpinning project design was that NGO-supported in-service training can and must play an active role in changing pre-service training. This project sought to do more than just advocate for change. In-service trainers therefore included trainers or lecturers from training colleges who would later have a mandate to review and revise preservice curricula. Their engagement in co-developing the in-service training modules has built their capacity and confidence for (re-)developing modules for pre-service use. So far, several modules in each country have been tested with student teachers in teacher training institutions. Feedback from the student teachers has been positive regarding the value of the training, not just in explaining inclusive education and demonstrating learner-centred 
pedagogy that is not yet routinely used in colleges, but in helping them rethink what it means to be a teacher. As one put it:

“This programme has really changed how I used to perceive us as a teacher...I have learned that being a teacher is firstly not about you standing in front and making your learners copy, copy, copy but it is about you being a facilitator.”

(Little 2018)

The biggest hurdle, inevitably, is to encourage and support teacher training institutions and ministries of education to formalise the adaptation and adoption of the training and action research approaches into pre-service curricula to ensure consistent messages and pedagogy throughout pre- and in-service training nationally (Juma et al 2017b); a phase the project is currently working on.

In the NGO world, demonstrating results is vital. Teachers engaging in in-service training deserve to not have their time wasted, to enjoy the learning experience and come away with tangible professional development benefits. So far, only the Zanzibar project has been independently evaluated, revealing a wealth of evidence regarding the potential of the training to effect change among teachers, schools and communities (McKinney 2019).

Teachers report and demonstrate increased motivation in general, skills and confidence to teach diverse learners, and greater empathy towards learners and community members with disabilities. Parents report improved school-community co-operation, and teacher support for their children, including those with disabilities. Trainers report improved self-confidence and willingness to contribute to discussions about training development. School inclusion teams have begun identifying and addressing barriers to inclusion. Numbers of learners with disabilities in the eight pilot schools in Zanzibar more than doubled (2015-2018) from 102 to 233, with fewer learners dropping out and many returning to school (McKinney 2019, 17).

\section{Countering Pervasive Quick-and-Dirty Approaches}

While the Zambia/Zanzibar project is a relatively small-scale pilot, it offers important evidence to counter pervasive NGO and donor-supported 'quick-and-dirty' cascade trainings. The ideas behind the project are not ground-breaking. The approach will be familiar to 
anyone who has been researching or advocating for improved teacher education for inclusion for the last 25 years:

- Do not expect over-night change.

- Provide experiential learning opportunities.

- Empower teachers with critical-thinking and problem-solving skills

- Do not work on in-service training in isolation from pre-service.

These messages have been floating around since Salamanca, so why are such approaches not yet routine in all NGO and donor-supported inclusive education programmes? The answers are complex; no single reason applies to every context, programme or organisation. We discuss the factors that most commonly feature in the inclusive education initiatives we encounter through our network and consultancies.

\section{Collaboration and Exchange}

It is no coincidence that two of EENET's three domains for change in inclusive education are 'collaboration' and 'exchange’. Since 1997 we have seen how NGOs rarely work together and often have weak track records in collaborating with grassroots stakeholders (teachers, learners and parents), a situation that has not changed much:

With a few exceptions... most organisations appear to be doing their own thing, competing for funds and attention like never before.

(Glennie 2016)

We recognised that progress in inclusive education might depend on facilitation of a more collaborative culture within the sector, in which all actors openly exchange and discuss information and 'redouble their efforts to work together, meet together and build a collective front.' (Glennie 2016). The current weak commitments to collaboration and exchange among many NGOs fuels the continuation of teacher education programmes based on already refuted assumptions. 


\section{Transparency and Learning}

Evaluations help organisations learn about the processes and results of their interventions, but few evaluation reports are published, making it almost impossible for other organisations to learn from the successes or mistakes of colleagues in the sector. If evaluation results are released, it is often as a selective summary or publicity-focused case study, lacking critically reflective analysis. We know, from our own experience of conducting evaluations, that recommendations are usually seen by a few already-involved personnel while other NGOs do not access the lessons learned to help them avoid making the same mistakes or build on promising ideas. As consultants, we learn extensively from these evaluations, but that information is of limited use in the heads of a privileged few. EENET has the mechanism, reach and reputation to share valuable lessons from evaluations globally, but rarely gets the mandate from NGO clients. Inclusive education programme implementers and their donors urgently need to embrace a culture of transparency, allowing others to learn from experience in the field.

A further challenge to learning comes when organisations see reporting and evaluation as a bureaucratic exercise to please donors. The problem noted earlier, of inclusive education programmes lacking personnel with education expertise or backgrounds, may contribute to a lack of interest in genuinely learning from an evaluation rather than processing it as an administrative exercise. While the notion of ongoing monitoring and 'real-time evaluation'3 is gaining ground in humanitarian and development programming (Herson and Mitchell 2005), embracing evaluation and reflection as an integral part of every inclusive education initiative's learning journey is still far from the norm.

While some evaluations might contain data that needs to remain unpublished for data protection reasons, that does not explain why NGO guidance and training materials developed for use in their projects or partner schools often remain secret. Potentially, a wealth of innovative approaches to training which challenge false assumptions remain inaccessible to those outside the organisations developing them. Encouragingly, some are very willing to share their education guidance and training resources for free: Save the Children (e.g. 2018 and 2019) has been prominent in publishing open access materials or 
materials under creative commons licences in recent years. However, uptake of open source resources is often hampered by the 'not invented here' culture, where a 'solution originating from another organisation is an endorsement of that solution, and by extension, praise for the originating organisation’ (Elrha 2018, 48). As Elrha (2018, 48) describes, humanitarian organisations are in competition for funding and resources and therefore 'disincentivised from commending each other's achievements...[and] unwilling to adopt others’ solutions’.

The problem extends beyond the lack of willingness to use someone else's ideas. Evidence suggests that capacity and confidence to take a small idea from another organisation and adopt, adapt and scale it up is also lacking due to 'a lack of dedicated tools or other forms of support for innovators looking to scale' (Elrha 2018, 32). While this evidence from Elrha relates to the humanitarian sector we argue it is relevant to inclusive education within the development sector also. The ambitions kick-started by Salamanca will be constantly hindered without effective evaluation, improved sharing of ideas and support to help implementers understand how to expand their own and each other's good ideas from isolated pilots to wider-scale reform.

\section{Field and Academic Interaction}

Inclusive education and teacher education programmes in the global south offer a wealth of research opportunities, from which both academic outputs and practical learning resources could emerge. There is a role for academic researchers to collaborate with field-based education workers to reflect, learn, document and exchange experiences - providing access to evidence, voices and perspectives not otherwise available. As shown by the Carnegie UK Trust and the Joseph Rowntree Foundation, universities' research results are 'little used by policymakers and practitioners even though they are the most trusted source of evidence' (McCormick 2013 as quoted in Shucksmith 2016, 1)

In the past, NGO staff might dismiss academic research as inappropriate because of its inaccessibility; they and their grassroots stakeholders had limited opportunities to access academic books or journals, removing the incentive to, or sense of value for, collaborating with academic researchers. The internet and open source movement is slowly improving this situation but not fast enough: the non-academic co-authors of this article experience 
frustration at being unable to access academic sources listed online, without which their work is deemed insufficiently rigorous for academic publishing - a vicious circle. The glass wall between academia and development practice persists, even in the field of education.

Mutually beneficial cross-over between academic research on teacher education and teacher education within NGO- and donor-supported programmes may also be hampered by fundamentally different working environments and cultures. For instance, an inclusive education project evaluation typically takes a few weeks to a couple of months, with workload pressures often resulting in last-minute planning. It would likely all be over before an academic researcher had gained ethical permission to engage. Facilitating collaboration between inclusive education field staff, stakeholders, and academics might therefore require significant changes or compromises in ways of working on both sides - so that collaborative partners are 'open and aware of each other's expectations from the onset' and taking responsibility for joint learning that is 'aimed at bridging the intellectual and cultural divide between academics and NGO practitioners’ (Aniekwe et al. 2012).

\section{Power Relations and Theories of Change}

Despite being trendy, theory of change is not always used to its full potential within international development. A sound theory of change process invites planners to make explicit their assumptions about their work and related contexts, leading to more accurate decisions about needed changes and how they can contribute to those changes (Vogel 2012). However, theory of change requires organisations to reflect on and challenge their existing ways of working - to question why they do things they may have been doing for years. In the context of inclusive education teacher education, this might mean asking why we use cascade training and how we think this is effecting change. This process of reflection and self-critique cannot be done without considering power relations, within the project or organisation or between the organisation and its donors. Such power dynamics can 'limit the ability to challenge established ways of working' (Vogel 2012, 9)

If those with decision-making power in a teacher education project, implementing organisation, or donor, hold firm to their assumptions about the nature of training, and are reluctant to reflect critically on their work, then even the most compelling evidence from 
alternative ways of training teachers is unlikely to have an impact on their approach to project design.

Power relations internally within hierarchies in organisations, as well as externally between donors, partners and stakeholders constrain the extent to which differences can be acknowledged. This is especially the case when theory of change thinking takes place in the context of highly pressured negotiations around results-based performance management. There may be a retreat to technocratic or 'ideal' programme strategies that are poorly suited to the context but are in keeping with organisational norms and therefore more acceptable to senior managers.

(Vogel 2012, 28)

\section{Expertise}

Finally, there is the issue of education expertise and competence. Where inclusive education teacher education projects are managed or funded by personnel lacking sufficient familiarity with how inclusive education evolves, or how adults/teachers learn, they may be more likely to cling to default positions; preferring isolated short cascade trainings, rapidly reaching impressive numbers of teachers, regardless of efficacy when viewed as a theory for how sustainable change in teaching happens.

\section{Moving Forward}

There remains a vast array of challenges ahead in achieving the vision of inclusive education set out in the Salamanca Statement and reinforced in subsequent international instruments. Within the sub-sector of teacher education, the challenges are daunting given the millions of diverse learners still excluded from and within education and the relative lack of resources available to help teachers become confident and competent inclusive practitioners. However, EENET's experience in general over the last 22 years, and specifically learning from the Zambia/Zanzibar project, offers opportunities where we believe investment would speed up or improve the quality of change. 
Top of our list is the need for all actors working on inclusive education teacher education to invest in documenting their work, from a critically reflective, not just self-promotional, perspective. More actors should openly embrace and invest in understanding how to learn from and expand on others' experiences. Improved transparency is the only way for vital lessons to be shared and pervasive false assumptions to be challenged. Implementing and funding organisations need to work on a cultural shift so that learning about and improving quality of teacher education for inclusion takes priority, over rapidly achieving impressive numbers of superficially and unsustainably trained teachers. The entire field of teacher education - for inclusion and beyond - needs to be accorded a greater sense of professionalism; moving away from the idea that anyone can plan and implement training on inclusion to a recognition that teaching is a complex and highly skilled profession that demands the same level of expert input that training doctors would receive. None of these changes requires impossibly high levels of additional funding. For the most part, they are changes in attitudes, and changes in how things are done and by whom.

1 https://data.worldbank.org/topic/education Last accessed 25/02/2019

2 EENET's Theory of Change is explained within an accessible PowerPoint presentation that includes an audio soundtrack. It can be requested using the link on the website: www.eenet.org.uk/about/eenets-theory-of-change/

3 Real time evaluation is ongoing evaluation which seeks to learn lessons during the course of an initiative to enable changes or improvements to happen before the end of the project.

\section{References}

3iE. 2016. The impact of education programmes on learning and school participation in lowand middle-income countries, Systematic Review 7. London: International Initiative for Impact Evaluation. Accessed February 172019 https://www.3ieimpact.org/evidence-hub/publications/systematic-reviewsummaries/impact-education-programmes-learning-school-participation-low-and$\underline{\text { middle-income-countries }}$

Ackah-Jnr, Francis R. and Joyce B. Danso. (2019) "Examining the physical environment of Ghanaian inclusive schools: how accessible, suitable and appropriate is such 
environment for inclusive education?” International Journal of Inclusive Education. 23 (2): 188-208. doi:10.1080/13603116.2018.1427808

Ainscow, Mel. 2013. "From special education to effective schools for all: widening the agenda.” In The Sage Handbook of Special Education, Edited by L. Florian.

Ainscow, Mel and Abha Sandill. 2010. "Developing inclusive education systems: the role of organisational cultures and leadership” International Journal of Inclusive Education 14 (4): 401-416. doi:10.1080/13603110802504903

Anderson, Gary. 2017. "Participatory action research (PAR) as democratic disruption: new public management and educational research in schools and universities” International Journal of Qualitative Studies in Education. 30(5):432-449. doi:10.1080/09518398.2017.1303211

Aniekwe, Chika Charles, Rachel Hayman, and Anna Mdee with Job Akuni, Priya Lall and Daniel Stevens. 2012. Academic-NGO Collaboration in International Development Research: a reflection on the issues. Working Paper. Development Studies Association. Accessed February 182019 https://www.intrac.org/resources/academicngo-collaboration-international-development-research-reflection-issues/

Bolton, Laura. 2018. Effective learning strategies to improve basic education outcomes. K4D Helpdesk Report. Institute of Development Studies. Accessed January 202019. https://assets.publishing.service.gov.uk/media/5b18f322e5274a18f134fd1b/Effective Learning_Strategies.pdf

Byrne, Bronagh. 2013. "Hidden contradictions and conditionality: conceptualisations of inclusive education in international human rights law.” Disability \& Society 28(2):232-244. doi:10.1080/09687599.2012.699282

DEVCO (International Cooperation and Development). 2014. Teacher Policy, Governance and Training: Issues and evidence to support programming. DEVCO B4 Education Discussion Paper. Accessed February 52019. https://europa.eu/capacity4dev/file/23095/download?token=Y6V1-zZo

DFID (Department for International Development). 2018a. Annual Review Report, Leh Wi Learn - Sierra Leone Secondary Education Improvement Programme. Department for 
International Development. Accessed January 162019.

https://devtracker.dfid.gov.uk/projects/GB-1-205234/documents

DFID (Department for International Development). 2018b. Annual Review Report, Learning for All Rwanda', Department for International Development. Accessed January 2019: https://devtracker.dfid.gov.uk/projects/GB-1-204463/documents

DfE (Department for Education). 2018. Initial Teacher Training Bursaries Funding Manual. 2018 to 2019 academic year. London: Department for Education. Accessed January 302019.

https://assets.publishing.service.gov.uk/government/uploads/system/uploads/attachme nt_data/file/697803/Initial_Teacher_Training_bursaries_funding_manual_18-19.pdf

Education Commission. 2016. The learning generation: Investing in education for a changing world. New York: International Commission on Financing Global Education Opportunity. Accessed January 222019.

https://report.educationcommission.org/wpcontent/uploads/2016/09/Learning_Generation_Full_Report.pdf

Elrha. 2018. Too Tough to Scale? Challenges to Scaling Innovation in the Humanitarian Sector. London: Elrha. Accessed January 222019. https://www.elrha.org/researchdatabase/too-tough-to-scale-challenges-to-scalinginnovation-in-the-humanitarian-sector/

ESRC (Economics and Social Research Council). 2018. ESRC-DFID Research for Policy and Practice: Quality teaching. ESRC and DFID. Accessed February 22019. https://www.theimpactinitiative.net/resources/esrc-dfid-research-policy-and-practicequality-teaching

Evans, David. and Anna. Popova. 2016. What Really Works to Improve Learning in Developing Countries? An Analysis of Divergent Findings in Systematic Reviews. Oxford University Press on behalf of the World Bank. Accessed February 32019. https://elibrary.worldbank.org/doi/pdf/10.1093/wbro/lkw004

Florian, Lani. and Holly Linklater. 2010 "Preparing teachers for inclusive education: using inclusive pedagogy to enhance teaching and learning for all.” Cambridge Journal of Education 40(4):369-386 doi:10.1080/0305764X.2010.526588 
Glennie, Jonathan. 2016. If the world is getting better, where next for NGOs? Accessed January 2019: www.theguardian.com/global-development/2016/jan/06/world-gettingbetter-non-governmental-organisations-charities-sector

Herson, Maurice. and John Mitchell. 2005. Real-Time Evaluation: where does its value lie? Humanitarian Exchange, 32:43-45

Hick, Peter. Yvette Solomon, Joseph Mintz, Aikaterini Matziari, Finn Ó Murchú, Kathy Hall, Kevin Cahill, Catriona Curtin and Despoina Margariti. 2018. Initial Teacher Education for Inclusion. Phase 1 and 2 Report. Research Report No.26. Trim: National Council for Special Education. Accessed January 252019. https://www.researchgate.net/publication/332278214_Initial_Teacher_Education_for_ Inclusion_Phase_1_and_2_Report/download

IDDC (International Disability and Development Consortium) .2016. \#CostingEquity. The case for disability-responsive education financing. International Disability and Development Consortium Inclusive Education Task Group and Light for the World. Accessed January 15 2019. https://www.eenet.org.uk/costingequity/costingequity-thecase-for-disability-responsive-education-financing-summary-report/

Juma, Said, and Elina Lehtomäki. 2016. Moving towards inclusion: how Zanzibar succeeds in transforming its education system?. International journal of inclusive education, 20(6), 673-684. doi:10.1080/13603116.2015.1111442

Juma, Said, Elina Lehtomäki and Aimo Naukkarinen. 2017a. Scaffolding teachers to foster inclusive pedagogy and presence through collaborative action research. Educational Action Research, 25(5), 720-736. doi:10.1080/09650792.2016.1266957

Juma, Said, Elina Lehtomäki and Aimo Naukkarinen. 2017b. Developing inclusive preservice and in-service teacher education: Insights from Zanzibar primary school teachers. International Journal of Whole Schooling, 13. Accessed February 52019. http://www.wholeschooling.net/Journal_of_Whole_Schooling/articles/133\%20Juma\%20Lehtom\%C3\%A4ki\%20\&\%20Naukkarinen\%202017.pdf

Kareithi, Roselyn N. M. and Crick Lund. 2012. "Review of NGO performance research published in academic journals between 1996 and 2008.” South African Journal of Science 108(11/12). Accessed January 262019. http://www.scielo.org.za/scielo.php?script=sci_arttext\&pid=S0038$\underline{23532012000600013}$ 
Kennedy, Aileen. 2005. "Models of Continuing Professional Development: a framework for analysis.” Journal of In-service Education. 31(5):240. doi:10.1080/13674580500200277

Laluvein, Jackie. 2010. “School inclusion and the ‘community of practice'.” International Journal of Inclusive Education. 14(1):35-48. doi:10.1080/13603110802500950

Lewis, Ingrid 2011. Inclusive Education: Quality Education for All Project. World Vision Armenia. Final Evaluation. April 2011. Unpublished report. EENET and World Vision

Lewis, Ingrid 2014. Evaluation of the NFU Supported Inclusive Education Project in Zanzibar. Unpublished report. EENET and Norwegian Association for Persons with Developmental Disabilities

Lewis, Ingrid 2016. “Creating a Theory of Change for EENET.” Enabling Education Review 5. UK: Enabling Education Network. Accessed May 172019. https://www.eenet.org.uk/enabling-education-review/enabling-education-review-6/

Little, Duncan. 2018. Inclusive Education Training Report, UNZA, Lusaka, Zambia. Phase 1: 25th - 26th July 2018. Unpublished project report. EENET and NAD.

Male, Chata. and Quentin T. Wodon. 2017. Disability gaps in educational attainment and literacy (English). The price of exclusion: disability and education. Washington, D.C.: World Bank Group. Accessed January 302019. http://documents.worldbank.org/curated/en/396291511988894028/pdf/121762replacement-PUBLIC-WorldBank-GapsInEdAttainmentLiteracy-Brief-v6.pdf

Malin, Joel R. and Christopher. Lubienski. 2015. “Educational Expertise, Advocacy, and Media Influence.” Education Policy Analysis Archives 23(6). Accessed May 52019. https://epaa.asu.edu/ojs/article/view/1706/1456

McClure, Dan and Ian Gray. 2015. Scaling: Innovation's Missing Middle. Paper submitted to World Humanitarian Summit 2015. Accessed January 302019. https://www.thoughtworks.com/insights/blog/scaling-innovations-missing-middle

McKinney, E. 2019. Evaluation of the NAD/NFU Supported Inclusive Education Project in Zanzibar. Unpublished report. Disability Included CC and NAD. 
Miles, Susie, and Anupam Ahuja. 2007. "Learning from difference: Sharing international experiences of developments in inclusive education”. In The Sage Handbook of Special Education. Edited by. L. Florian. London: Sage.

MEHE (Ministry of Education and Higher Education). 2015. Palestine Inclusive Education Policy. Ministry of Education \& Higher Education

Popova, Anna, David Evans and Violeta Arancibia. 2016. Inside In-Service Teacher Training: What works and how do we measure it? Washington, DC.: Rise Programme. Accessed January 272019. https://www.riseprogramme.org/sites/www.riseprogramme.org/files/inlinefiles/Evans_Inside_In_Service_Teacher_Training_CLEAN_v2016-06-22.pdf

MoE (Republic of Namibia Ministry of Education). 2013. Sector Policy on Inclusive Education. Republic of Namibia Ministry of Education

Prinsen, Gerard and Saskia Nijhof. 2015. "Between logframes and theory of change: reviewing debates and a practical experience.” Development in Practice. 25(2):234246. Doi:10.1080/09614524.2015.1003532

Riep, Curtis and Mark Machacek. 2016. School the Poor Profitably. The innovations and deprivations of Bridge International Academies in Uganda. Education International. Accessed February 3 2019. https://www.right-to-education.org/resource/schoolingpoor-profitably-innovations-and-deprivations-bridge-international-academies

Rieser, Richard, with Sue Stubbs, Juliette Myers, Ingrid Lewis, and Kalpana Kumar. 2013. Teacher Education for Children with Disabilities. Literature Review for UNICEF REAP Project. London: World of Inclusion. Accessed January 182019. https://www.eenet.org.uk/resources/docs/Teacher_education_for_children_disabilities litreview.pdf

Save the Children. 2018. Improving Learning Environments Together in Emergencies (ILET) Package. Oslo: Save the Children Norway. Accessed January 302019. https://www.reddbarna.no/nyheter/improving-learning-environments-together-inemergencies

Save the Children. 2017. The Foundations of Tanzanian Teaching: Training for educators in core teaching competencies. London: Save the Children UK. Accessed January 8 
2019. https://resourcecentre.savethechildren.net/library/foundations-tanzanianteaching-training-educators-core-teaching-competencies

Sharma, Umesh, Tim Loreman, and Chris Forlin. 2012. "Measuring teacher efficacy to implement inclusive practices”. Journal of Research in Special Educational Needs 12(1):12-21. doi:10.1111/j.1471-3802.2011.01200.x

Shucksmith, Mark. 2016. How can academics and the third sector work together to influence policy and practice? Dunfermline: Carnegie Trust. Accessed January 152019. https://www.rri-tools.eu/-/how-can-academics-and-the-third-sector-work-together-toinfluence-policy-and-practice

Stein, Danielle and Craig Valters .2012. Understanding Theory of Change in International Development. London: Justice and Security Research Programme/LSE. Accessed January 292019.

http://www.lse.ac.uk/internationalDevelopment/research/JSRP/downloads/JSRP17.Va lters.pdf

UN (United Nations). 2006. United Nations Convention on the Rights of Persons with Disabilities. Accessed January 2019: www.un.org/disabilities/documents/convention/convention_accessible_pdf.pdf

UN (United Nations). 2015. Transforming our World: The 2030 Agenda for Sustainable Development. New York: United Nations

UN (United Nations). 2018. The Sustainable Development Goals Report 2018. New York: United Nations

UNESCO (United Nations Educational, Scientific and Cultural Organization). 1994. The Salamanca Statement and Framework for Action on Special Needs Education. Adopted at the World Conference on Special Needs Education: Access and Quality, Salamanca, Spain, 7-10 June, 1994. Paris: UNESCO.

UNESCO (United Nations Educational, Scientific and Cultural Organization). 2017. Accountability in Education. Meeting our commitments. Global Education Monitoring Report 2017/18, Paris: UNESCO

Vogel, Isabel. 2012. Review of the use of 'Theory of Change' in international development. London: UK Department for International Development. Accessed January 152019. http://www.theoryofchange.org/pdf/DFID_ToC_Review_VogelV7.pdf 
Westbrook Jo, Naureen Durrani, Rhona Brown, David Orr, John Pryor, Janet Boddy and Francesca Salvi. 2013. Pedagogy, Curriculum, Teaching Practices and Teacher Education in Developing Countries. Final Report. Education Rigorous Literature Review. Department for International Development. Accessed February 42019. https://eppi.ioe.ac.uk/cms/Portals/0/PDF\%20reviews\%20and\%20summaries/Pedagog y\%202013\%20Westbrook\%20report.pdf?ver=2014-04-24-121331-867 